\title{
Prensa y democracia: una reflexión
}

institucionales.us.es/ambitos/

\section{Miguel Ángel Sánchez de Armas \\ Universidad lberoamericana Ciudad de México}

Me parece que es menester revisar, recuperar y revalorar a teóricos de la comunicación que tuvieron un enfoque humanista y no mecanicista, para entender a los medios en su carácter de herramientas políticas. Los medios + , Perogrullo dixit, son un componente importante del sistema de dominación social. Y si bien impulsan y en ocasiones reformulan los valores y prácticas de la democracia, ello no les quita el carácter de correas transmisoras de los sistemas dominantes. Pero en una relación

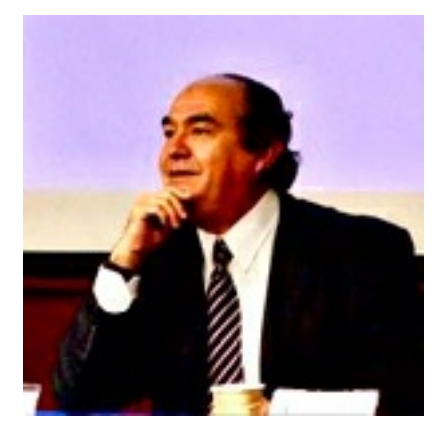
dialéctica, la democracia también es el principio constructor de los sistemas de comunicación que llamamos masivos, o sociales. De esta manera, la información regresa sobre quienes toman decisiones.

Sin embargo, la comunicación tiene una vida concreta que se desarrolla día con día en distintos medios -prensa, radio, televisión, cine- que, sobre todo en sus segmentos informativos, acusa problemas de auditorio: la prensa tiene un nivel de lectores en descenso y los noticiarios de radio y TV difícilmente superan en rating a los programas de entretenimiento.

Lo que resulta de esta situación es la paradoja de la importancia que atribuimos a los medios en la democratización de las sociedades y la importancia relativa que éstas dan a aquellos. Parece no haber reciprocidad. Esto nos lleva a la reflexión de que, en tal contexto, el valor de los medios estriba quizá más en su carácter político que en su naturaleza comunicadora o de difusión.

El hombre medio parece haber decidido que la importancia y la credibilidad de los medios puede llegar a reemplazar su opinión y actuación, reemplazo que se antoja como letargo, como alejamiento de los hombres de la actividad que a lo largo de su historia les ha caracterizado: la política.

No parece extraño entonces que en la sociedad contemporánea algunos consideren el quehacer político como patrimonio casi exclusivo de los medios. Una realidad que podemos constatar cada vez con mayor frecuencia es la extendida percepción de la existencia de los hechos merced a su inclusión en los medios. Y como consecuencia la sensación de que lo que no nos es servido por los medios no existe, o corresponde a una dimensión ajena.

Walter Lippmann * entendió bien los alcances movilizadores de la prensa y su función al interior de la sociedad y llegó a una aguda conclusión: la prensa no puede suplir a las instituciones políticas. Mejorar los sistemas de recolección y presentación de las noticias 
no es suficiente para perfeccionar la democracia, pues verdad y noticia no son sinónimos. La función de la noticia es resaltar un hecho o un evento. La de la verdad, sacar a luz datos ocultos.

¿Hasta qué punto la prensa reconoce pero se beneficia de este rol? ¿Tiene realmente la llamada sociedad civil alguna posibilidad de inhibir la pretensión de los medios de ser los paladines de la democracia cuando manifiestamente están lejos de serlo, al menos como continuidad? ¿Existe la posibilidad de configurar mecanismos de comunicación que permitan avanzar hacia el ideal de democracia que cada sociedad tiene?

Quizá un camino inicial pase por desconfiar de afirmaciones complacientes y tranquilizadoras de la especie: "prensa y democracia se encauzan y determinan recíprocamente". No hacemos bien a uno ni a otro concepto. No entronicemos a la prensa como defensora de la democracia, démosle la responsabilidad que le corresponde: informar a la sociedad. De nuevo Lippmann: la prensa no puede suplir a las instituciones políticas. Perfeccionar la democracia requiere mejores instituciones, no necesariamente más medios.

Debemos preguntarnos si en el fondo no hemos tenido que aprender a vivir con un nuevo fundamentalismo, que podría expresarse así: los medios -como continuidad- se consideran depositarios de la verdad y de las necesidades sociales, sobre todo si de derechos democráticos y de justicia se trata. Pero no sólo por la actividad que les es propia, que es la de investigar y recoger los hechos cotidianos, sino porque el discurso de reclamo democrático consideran haberlo ganado gracias a su experiencia de relación con los grupos de poder.

Siguiendo esta línea de pensamiento, la información no es un bien que se ofrece a la sociedad para que ésta configure los mecanismos de relación que considere pertinentes con el poder, poder que -además- la propia sociedad ha otorgado, sino que se convierte en patrimonio para una relación de poder a poder.

Luce mucho más realista asumir que el panorama de la comunicación es más amplio de lo que pensábamos y también mucho más accidentado, para ubicar a los medios como un elemento -importante, sí, insoslayable también- en la construcción de una sociedad más democrática, pero de ningún modo como el motor de la democracia. Quizá fuera conveniente recuperar la suspicacia política con que fueron escudriñados los hechos sociales en las décadas de los setenta y ochenta -acusadamente las manifestaciones culturales-, con la ventaja de la mirada retrospectiva que nos permite distanciarnos de los determinismos, para fabricar nuevas herramientas de análisis y conocimiento de los medios contemporáneos. Pienso que de esta manera podemos construir el camino que lleve a los medios a la construcción de los valores que exige la complejidad del mundo postmoderno.

\section{BREVE SEMBLANZA DEL AUTOR:}


Miguel Ángel Sánchez de Armas, periodista mexicano, se doctoró por la Universidad de Sevilla bajo la dirección del profr. Dr. Ramón Reig. Fundó y dirigió las revistas Mexicana de Comunicación, Mexicana de Cultura Política y Mexican Journal of Communication. Es autor de diversos libros, entre ellos Apuntes para una historia de la televisión mexicana, En estado de gracia: conversaciones con Edmundo Valadés y El peligro mexicano: comunicación y propaganda en la expropiación petrolera de 1938. Ha participado en numerosos congresos en México y otros países y es profesor investigador de larga trayectoria.

Ámbitos. Revista Internacional de Comunicación, n.40, edición de primavera, 2018. 